\title{
EDUCAÇÃO TÉCNICA E AS MUDANÇAS DA METODOLOGIA SENAI APÓS A BNCC
}

\author{
Rafael Oliveira Costa Domingos ${ }^{1}$ \\ ${ }^{1}$ Centro Universitário de Mineiros (UNIFIMES-GO), Mineiros - GO, Brasil.
}

\begin{abstract}
Resumo: Este trabalho apresenta a Educação Técnica a partir da proposta Metodológica do SENAI - Serviço Nacional de Aprendizagem Industrial que, por ocasião da nova BNCC, ajusta seu plano de ação, no intuito de colaborar com o desenvolvimento professional de indivíduos perpassando pela diversidade cultural e aspectos socioemociais. Um dos focos da formação técnico-profissional desenvolvida pelo SENAI é o desenvolvimento de competências e habilidades em indivíduos inclusos no setor industriário ou autônomo, que buscam conhecimentos em áreas gerais ou em alguma especificidade. A partir do estudo da Metodologia SENAI, foi possível perceber que o ideal técnico cria uma ponte de conhecimento entre indivíduo e a indústria - que hoje, mais do nunca, prima pela busca de mão de obra qualificada, que atenda à demanda mercadológica. Com isso, as Diretrizes Curriculares do SENAI pontuam três caminhos essenciais para formação, que são: Perfil Profissional, Desenho Curricular e Práticas Pedagógicas. Em um mundo globalizado, em que a educação e seus eixos se encontram entronizados em quase todos os setores da sociedade, criar elos dialógicos, tais como os estabelecidos entre a Metodologia SENAI e a BNCC são fundamentais. Discussão como essa não pode ficar fora do contexto de formação de professores, haja vista a amplitude e a abrangência da área educacional.
\end{abstract}

Palavras-chave: Metodologia. Senai. Educação Técnica.

Como citar: DOMINGOS, R. O. C. Educação técnica e as mudanças da metodologia SENAI após a BNCC. Revista Científica Novas Configurações - Diálogos Plurais, Luziânia, v. 1, n.1, p. 52-57, 2020. https://doi.org/.10.4322/2675-4177.2020.007

\section{INTRODUÇÃO}

O ensino técnico, por muito tempo, foi entendido como um ensino reprodutivista, que, por sua vez, produzia operários de mão de obra especializada para atender o mercado de trabalho. Entretanto, não é bem assim que essa metodologia se encontra hoje, posto que a perspectiva é de que o ensino técnico acolhe aqueles que estão à margem do processo.

Segundo a Metodologia SENAI (2019), as competências e habilidades estão ligadas diretamente à vida pessoal do indivíduo em que a sua bagagem cultural deve e vai ser aproveitada, visto que o novo objetivo da indústria é desenvolver habilidades e competências assim como a BNCC direciona a nova reforma do ensino médio para o ensino técnico, fazendo com que a ideia seja pertinente.

Apesar de o setor empresarial primar por uma mão de obra de qualidade e barata, a Metodologia SENAI de Educação Profissional faz com que esse indivíduo se reconheça e saiba valorizar o seu trabalho, pois o desenvolvimento integrado junto com o aprender a aprender, gerando uma qualificação com senso de criticidade e ética profissional.

A nova metodologia recebeu impactos após a sua $4^{\mathrm{a}}$ Revolução Industrial, o ensino técnico se tornou mais humanizado e, a cada vez que o contexto social requer demandas diferenciadas, o sistema educacional é atualizado com foco na humanização desse sujeito.

No ano de 2019, a Metodologia do SENAI foi apresentada durante a $4^{\text {a }}$ Jornada Pedagógica, em Brasília, nos dias 31 de julho e 01 de agosto. No cenário atual de inovação e crescimento tecnológico, o

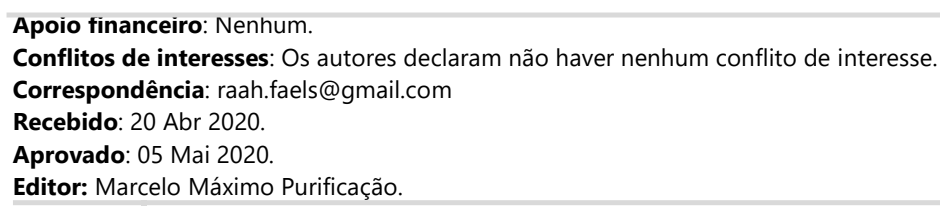

Este é um artigo publicado em acesso aberto (Open Access) sob a licença Creative Commons Attribution, que permite uso, distribuição e reprodução em qualquer meio, sem restrições desde que o trabalho original seja corretamente citado. 
SENAI atualizou sua forma de ensino trazendo novas ferramentas e recursos para os alunos se tornarem sujeitos (pró) ativos em seu aprendizado. Analisando minuciosamente a Metodologia, observa-se que a mesma fornece subsídios suficientes para emancipar e protagonizar um indivíduo socialmente e se apoiando em Gil (1999), o método científico é um conjunto de procedimentos intelectuais e técnicos utilizados para atingir o conhecimento. Para que seja considerado conhecimento científico, é necessária a identificação dos passos para a sua verificação, ou seja, determinar o método que possibilitou chegar ao conhecimento. Dentro do exposto como objetivo geral, irá se apresentar a metodologia da educação profissional - na perspectiva de criar um pensamento crítico sobre a metodologia da escola técnica, descrevendo os efeitos da aplicação da Nova Metodologia Senai de ensino.

O pensamento de um ensino reprodutivista é constante dentro de um ensino técnico, mas é preciso olhar a fundo e entender por que esse pensamento não muda, visto que as metodologias educacionais estão se atualizando a cada tempo que se passa. Para que não exista um ensino reprodutivista, é preciso rever os métodos de formação assim como os métodos avaliativos, pois se há uma permanência em um cunho somático, consequentemente será uma formação de reprodução objetiva, não de competência, mas sim de metas quantitativas. A análise contará com base na metodologia SENAI 2019, promovendo um estudo em cima do que a metodologia chama de Perfil Profissional, Desenho Curricular e Prática Pedagógica. Dentro dessa análise, poderá se promover um entendimento de como a didática tem sido aplicada ao ensino técnico. Por métodos de pesquisa bibliográfica de cunho qualitativo, percebe-se que um ensino que tem como objetivo mudar a realidade daquele que se encontra à margem do processo, do segregado que mesmo estando em conjunto social se sente isolado e, para isso, é preciso entender a posição que o indivíduo se encontra para, assim, oferecer meios para que ele possa se desenvolver, corroborando com a ideia de Freire (1979):

\begin{abstract}
Não é possível fazer uma reflexão sobre o que é educação sem refletir sobre o próprio homem. [...] comecemos por pensar sobre nós mesmos e tratemos de encontrar, na natureza do homem, algo que possa constituir o núcleo fundamental onde se submete o processo de educação. Qual seria este núcleo palpável a partir de nossa própria experiência existencial? Este núcleo seria o inacabamento ou a inconclusão do homem (FREIRE, 1979, p. 27).
\end{abstract}

Nessa perspectiva, deve-se compreender e analisar sua exemplificação frente às outras pessoas, em que as mesmas pensam que somente com um conhecimento prévio, podem expressar suas opiniões sem levar em conta quais benefícios esse método de ensino traz para o âmbito social.

Problematizar a metodologia é conhecê-la ao ponto de estar apto a sugestionar e comparar seus métodos, trazendo a pesquisa para aplicação do cenário atual.

\title{
2 APRESENTANDO A METODOLOGIA
}

A prática Pedagógica da Formação, com base em competências do SENAI, propõe uma atuação integrada entre docentes, coordenações Técnicas e Pedagógicas, para uma promoção no paradigma do processo "ensino-aprendizagem" para que o aluno passe a ser o "protagonista do processo de aprendizagem" e o docente "protagonista do processo de ensino e mediador do processo de aprendizagem" visto que essas mudanças partiram com o desenvolvimento social, pois hoje a indústria precisa de um trabalhador com competência profissional, competência específica e competência socioemocional, não se sabe ao certo se é possível tornar alguém preparado emocionalmente para atuar dentro de qualquer esfera econômica, pois as questões emocionais estão ligadas diretamente à bagagem cultural de cada um, o que se pode fazer é mostrar como lidar com as emoções dentro de uma ética corporativa e ou em uma ética profissional como um todo. Não é errado ser vencido por suas emoções, pelo contrário é um grande ato de bravura e comprometimento lidar com suas emoções de forma consciente, em que a pessoa possa chegar na empresa e dizer “Olha, hoje não estou bem!", e a empresa entender que aquele funcionário não está inventando história para sair do horário de serviço, e essa confiança do funcionário para com a empresa é parte fundamental do desenvolvimento de uma competência, por isso, segundo Perrenoud (1999), a competência vem através da prática da habilidade e a execução atenciosa do conhecimento pensando em que mesmo se apoderando do saber, devemos praticar e compartilhar o nosso conhecimento com as demais pessoas, para que assim possa se dar sentindo à competência.

A Escola Técnica, que agora considera toda historicidade do indivíduo como parte de sua formação, se abdica de ser um ensino reprodutivista percebendo que não há um padrão comportamental das pessoas e de sua história cultural. Logo, à ideia de trazer essa nova perspectiva de ensino, o aluno passa a ser o protagonista da sua própria história e, com isso, o professor, que é o mediador do processo, deve-se aprimorar mais, apoiando-se em Freire (2006): 
É preciso que o (a) educador (a) saiba que o seu "aqui" e o seu "agora" são quase sempre o "lá" do educando, Mesmo que o sonho do (a) educador (a) seja não somente tornar o seu "aqui-agora", o seu saber, acessível ao educando, mas ir mais além de seu "aqui-agora" com ele ou compreender, feliz, que o educando ultrapasse o seu "aqui", para que este sonho se realize tem que partir do "aqui" do educando e não do seu (FREIRE, 2006).

Quando o aluno chega em um curso profissionalizante técnico, como por exemplo o Eletricista Industrial, que tem como função desenvolver projetos elétricos tanto quanto residenciais, prediais e industriais, a concepção de profissão passada anteriormente é de que o mesmo passará fiações dentro de uma casa, irá aprender sobre o que é corrente elétrica e coisas básicas de que um eletricista convencional faz, entretanto, a descrição e explicação da função de um eletricista industrial é de suma importância para o funcionamento de qualquer construção, seja ela civil ou industrial, e essa responsabilidade tem que ser passada para o aluno em formação.

E trabalhar isso de uma forma em que o aprendizado não se prenda ao ditado de que "o ensino técnico só se ensina a apertar o parafuso"; tal concepção deve ser alterada, as funções que um indivíduo pode ocupar dentro da indústria são inúmeras e cabe à instituição de educação promover competências e habilidades nesse aluno para que ele possa almejar cargos maiores dentro de uma empresa, e que ele possa reconhecer a sua trajetória educacional, por isso o professor deve ser o mediador deste processo de ensino, então quando (FREIRE, 2006) afirma que o estado em que o professor(a) está é o auge aonde o aluno quer chegar, cabe ao mesmo entender que o estado de aprendizagem que o aluno se encontra deve ser trabalhado não só dentro do seu nível de conhecimento mais como proporcionar maneiras de gerar novas competências e habilidades.

Dentro da metodologia, temos princípios norteadores, que são: Desenvolvimento de Capacidades: em que o fator potencial é trabalhado para se tornar uma competência do sujeito. Mediação da aprendizagem: assim como é nato do ser humano socializar e consigo ter um aprendizado difuso, cabe ao docente mediar essa aprendizagem trabalhando o conhecimento prévio mesmo que seja empírico ele é moldado para se tornar uma aprendizagem formal; Contextualização: a importância de trazer os aspectos de ensino deve ser trazido a realidade social político-econômica que a sociedade e a população brasileira vivem de acordo com (PERRENOUD, 2001) "toda situação didática proposta ou imposta uniformemente a um grupo de alunos é inadequada para uma parcela deles”. Não tem como mais um ensino ser padrão tradicional, porque está nítido que a aprendizagem não é igual para todos.

Além disso, a ênfase no aprender a aprender; para que haja essa singularidade em cada indivíduo, é preciso que o mesmo esteja apto para um processo de construção e desconstrução em todo instante, pois a múltipla inteligência precisa de várias maneiras de se pensar, pois não há uma só maneira de aprender para corroborar, como pronunciado por Vygotsky (2010):

A tarefa do docente consiste em desenvolver não uma única capacidade de pensar, mas muitas capacidades particulares de pensar em campos diferentes; não em reforçar a nossa capacidade geral de prestar atenção, mas em desenvolver diferentes faculdades de concentrar a atenção sobre diferentes matérias. (VYGOSTKY, 2010)

A Proximidade entre o mundo do trabalho e as Práticas Sociais; uma forte característica do curso técnico está em sua quantidade de aula prática.

Integração entre Teoria e Prática; a disponibilidade do acervo teórico dentro da metodologia SENAI é de grande expansão pois são serviços integrados, o material didático é feito pelo próprio sistema e, como é industrial, bastantes equipamentos estão disponíveis não só dentro da escola, mas como das indústrias parceiras também tornando a aprendizagem mais prática ainda.

Incentivo ao Pensamento Criativo e à Inovação; hoje o SENAI tem como um dos objetivos de um modo cooperado investir no docente para que o mesmo possa produzir projetos juntamente com indústria os alunos do SENAI têm ganhado destaque em projetos inovadores, logo a ideia do pensamento criativo é necessária para que o aluno seja incentivado.

Avaliação da Aprendizagem; hoje o processo avaliativo do SENAI utiliza de uma tríade de processos avaliativos são eles: diagnóstico, formativo e somativo, então todo o processo de aprendizagem do aluno é monitorado para que ele gere resultados e se esses resultados não estão na média, as coordenações entram em trabalho para sanar esse déficit toda componente de um curso seja ele técnico ou aprendizagem que engloba o sistema de jovem aprendiz em que é passado uma avaliação de reação e dentro de avaliação é diagnosticado em quais campos estão com anomalias e quando este percentual está baixo a intervenção acontece tanto no aspecto físico como no aspecto pedagógico. 


\title{
3 DESENHO CURRICULAR
}

O Desenho curricular é composto pela estrutura Curricular e pelo itinerário formativo e o itinerário formativo representa o conjunto de percursos de formação propiciados por uma instituição de educação profissional dentro de cada um dos diferentes segmentos profissionais como os quais atuais. De acordo com a metodologia SENAI (2019), o desenho do currículo é:

O resultado do processo de definição e organização dos elementos que compõem o currículo e que devem propiciar o desenvolvimento das capacidades demandadas pelo mundo do trabalho. Esse processo, ao traduzir pedagogicamente as competências de um Perfil Profissional, realiza a transposição das informações do mundo do trabalho para o mundo da educação e corresponde à segunda fase da Metodologia SENAI de Educação Profissional. O Desenho Curricular pode ser elaborado considerando uma ocupação ou um conjunto de ocupações de uma mesma área/segmento tecnológico. (SENAI, 2019 p. 47).

Quando se fala de currículo, não se pode pensar que é decreto que vai direcionar como o professor deve trabalhar, o currículo é um norte para onde a necessidade atual precisa ser suprida; no pensamento de SILVA, currículo é:

A análise sob o ponto de vista da etimologia do termo currículo que tem origem no latim, cujo significado é "pista de corrida", pode remeter ao entendimento de que currículo estabelece uma estreita relação com "identidade", na medida em que "no curso dessa corrida, que é o currículo, acabamos por nos tornar o que somos" (SILVA, 2007: p. 15).

O ensino educacional precisa de norteadores para que possam ser claros os objetivos a serem alcançados, a escola formal deve planejar o seu currículo pensando na comunidade em que está localizada e na escola técnica é importante atentar para as inter-relações existentes entre as fases da Metodologia de Educação profissional, considerando, sempre, os impactos que o currículo terá no desenvolvimento da pratica pedagógica.

A estratégia de elaboração do desenho curricular da metodologia SENAI é apresentada em um detalhamento sobre a organização dos cursos e programas de educação são ofertados pela metodologia SENAI (2019) da seguinte maneira:

\begin{abstract}
Iniciação Profissional: visa preparar para o desempenho de funções básicas, de baixa complexidade ou transversais a uma ou mais profissões, este curso não exige escolaridade mínima, estes cursos que dão iniciação a uma profissão são ensinamentos prévios que trazem noções para que o trabalhador execute suas tarefas conhecido o mínimo básico daquilo que opera, esse módulo tem uma carga horária maior que 8 horas ou menor que 160 horas.
\end{abstract}

Qualificação Profissional: visa preparar o indivíduo para o exército de uma profissão, referente a uma ou mais ocupações claramente identificáveis e reconhecidas pelo mercado de trabalho, conforme Perfis Profissionais definidos. Ainda assim são cursos que exigem escolaridade mínima, mas dispensam o conhecimento técnico como pré-requisito. Possuem carga horária mínima de 160 horas e são subdivido como: qualificação básica, qualificação técnica, ou competências do Perfil profissional de referência.

Aperfeiçoamento Profissional: visa atualizar ou aprofundar as competências de uma determinada ocupação, considerando o Perfil Profissional de referência de nível operacional, técnico ou estratégico. São cursos com carga horária entre 8 horas e 160 horas, que tem como requisito para ingresso uma formação inicial ou experiência profissional.

Especialização Profissional: Visa ampliar as competências de uma determinada ocupação, caracterizando uma nova função especializada. Pode desenvolver competências de nível operacional, tático ou estratégico, consideradas as referências estabelecidas pela legislação vigente. São cursos que têm como requisito para ingresso uma formação de nível equivalente e com cargas horárias mínimas de: 60 horas para especialização básica, 25\% da carga horária do curso de referência para Especialização Técnica e 30 horas para Especialização Superior.

Habilitação Técnica de Nível Médio: visa preparar o indivíduo para o exercício de uma profissão proporcionando o desenvolvimento de competências referentes a uma ocupação técnica claramente identificável e reconhecida pelo mercado de trabalho, conforme Perfil Profissional definido. São cursos que podem ser ofertados de forma subsequente, concomitante ou integrados ao ensino médio, atendendo aos critérios estabelecidos pela legislação. Possuem carga horária mínima de 800 horas.

Graduação Tecnológica: visa a formação de um Perfil Profissional de tecnólogo. São cursos de nível superior, abertos para a candidatos que tenham sido classificados em processo seletivo. É voltada para uma determinada área profissional e atende a critérios estabelecidos pela legislação. 
Graduação (Bacharelado ou Licenciatura): visa a formação de um Perfil Profissional de bacharel ou licencia. São cursos de nível superior, abertos a candidatos que tenham concluído o ensino médio ou equivalente e que tenham sido classificados em processo seletivo. É voltada para um campo de conhecimento específico e atende a critérios estabelecidos pela legislação.

Extensão: visam difundir conhecimentos para a comunidade em geral. São cursos vinculados ao ensino superior, destinados a candidatos que atendam aos requisitos estabelecidos em cada caso pela instituição de ensino. diz que:

O currículo técnico pensa nas condições que o trabalhador passará, por isso o Decreto № 5.154

\begin{abstract}
No Laboratório de Currículo foram reunidos profissionais da área docentes, especialistas, supervisão educacional para estudo do material produzido pela CBO -Classificação Brasileira de Ocupações e para análise das necessidades do próprio mercado de trabalho assim como o Catálogo Nacional de Cursos Técnicos. Uma sequência de encontros de trabalho previamente planejados possibilitou uma reflexão maior e produziu a construção de um currículo mais afinado com esse mercado (BRASIL, 2012, p. 6)
\end{abstract}

Em um pensamento educacional, o currículo envolve muito mais do que só conteúdos, processos ou estratégias. Se olharmos o currículo como uma análise crítica e reconstrução dos conhecimentos, valores e de costumes decorrentes ao desenvolvimento histórico de cada sociedade, é necessário cogitar mudanças temporais sejam elas em curto, médio ou longo prazo, assim como a indústria busca um trabalhador (pro) ativo, o trabalhador quer uma indústria que pense nele não como um capital humano, mas sim como um indivíduo que está ligado à vitalidade da empresa, pensar assim é pensar humano.

A escola não pode se prender ao pensamento de formar um operário apenas para reproduzir ordens, a escola tem que pensar além, deve educar e qualificar seus alunos para serem donos de empresa, assim como o melhor funcionário de uma empresa. Precisa-se formar cidadãos com amplos conhecimentos científicos e humanistas, defendendo um modelo de sociedade mais justo e solidário. "[...] a escolarização seria o fator determinante das relações sociais ou o caminho para a democratização e para a maior igualdade social" (ARAÚJO, 1995).

O currículo educacional da escola técnica não é centrado em conhecimentos e, sim, centrado em capacidades pensando em que cada indivíduo tem seu potencial que deve ser desenvolvido. Por isso, a Metodologia conta com três domínios da aprendizagem que são:

\footnotetext{
Cognitivo: relacionado ao modo como os indivíduos aprendem o "saber" de um determinado conteúdo, como os compreendem e analisam, isto é, o raciocínio e processo intelectual percorrido pelo o aluno na aquisição de novos conhecimentos.

Psicomotor: associado às habilidades do "saber fazer", envolvendo os órgãos do sentido e ativação neuromuscular para a realização de atividades especifica, passando pela percepção, pelos movimentos e pela comunicação não verbal:

Afetivo: ligado à área emocional e, portanto, ao "saber ser", representando atitudes, crenças, valores e juízos sobre os sujeitos e objetos que orientam o Aluno em comportamentos específicos durante a realização das tarefas.
}

Nessa perspectiva, o currículo com base cognitiva deve olhar as especificidades de seus trabalhadores sabendo que a bagagem cultural que ele estava inserido está em coexistência com a sua capacidade de aprender, logo, as exigências feitas para aquela pessoa devem ser ponderadas.

\title{
4 CONSIDERAÇÕES FINAIS
}

Observa-se que há um grande acervo de conhecimento a ser transferido para o público, para jovem, adulto, letrados e analfabetos, os patamares sociais podem ser atendidos dentro das suas especificidades.

A transferência do conhecimento será fragilizada, caso a docência ache dificuldade sobre a forma que a humanização do ensino técnico deve ser feita. É comum pensar que o planejamento de aula pode ser engessado, sem pensar nas singularidades de cada um, porém esse pensamento não pode coexistir com o ensino aprendizagem. O pensamento que é expresso dentro da metodologia é de que não existe um só método para ensinar, aprender e avaliar; existem mais métodos que trazem resultados mais específicos que podem contribuir para uma formação profissional e também social. 
Para um ensino que, para muitos, é dito como reprodutivista, a metodologia de 2019 está para mostrar que o reprodutivismo passou longe de ser cogitado, as indústrias hoje buscam um profissional qualificado e (pró) ativo capaz de desenvolver sua função e sub funções da área desejada.

Parte como objetivo da Metodologia desenvolver no indivíduo capacidades que o tornem apto para trabalhar na qualificação desejada e vai além não é só uma habilitação dentro da Classificação Brasileira de Ocupações, e sim de se reconhecer no âmbito social, pois a formação prevista pela metodologia SENAI é de capacidades específicas socioemocionais e, por fim, profissionais.

A escola formal, juntamente com suas adversidades e suas fragilidades, tem como objetivo comum trazer novas perspectivas para o ser humano, retirá-lo da condição excluso social e lhe dar a oportunidade de reconhecimento do seu valor, demonstrando que o mesmo possui o direito de ir e vir, assim como qualquer um que já se encontrou socialmente. A educação deve ser libertadora e emancipadora, não alienadora em nenhuma esfera social, esse sim é o objetivo da educação.

\section{REFERÊNCIAS}

BRASIL. Decreto $N^{\mathbf{0}} 5.154$ de 23 de julho de 2004. Regulamenta o $§ 2^{\text {o }}$ do art. 36 e os artigos. 39 a 41 da Lei n n $^{\circ} .394$, de 20 de dezembro de 1996, que estabelece as diretrizes e bases da educação nacional, e dá outras providências. Diário Oficial da União. Brasília, 26 de julho de 2004

\section{BRASIL. Ministério da Educação Centenário da Rede Federal de Educação Profissional e Tecnológica. 2007. \\ Disponível}

<http://portal.mec.gov.br/setec/arquivos/centenario/historico_educacao_profissional.pdf>. Brasília, 2019. Acesso em: 29 nov. 2019.

FREIRE, Paulo. Pedagogia da esperança: um reencontro com a Pedagogia do oprimido. São Paulo: Paz e Terra, 2006.

GIL, A. C. Métodos e técnicas de pesquisa social. 5.ed. São Paulo: Atlas, 1999.

PERRENOUD, Philippe. CONSTRUIR AS COMPETÊNCIAS DESDE A ESCOLA. 1990.

Disponível em: <https://abenfisio.com.br/wp-content/uploads/2016/06/Construir-ascompetec\%C3\%AAncias-desde-a-escola.pdf>. Acesso em: 08 out. 2019.

Construir competências é viras as costas aos saberes? 1999. Disponível em: <http://www.unige.ch/fapse/SSE/teachers/perrenoud/php_main/php_1999/1999_39.html>.

PERRENOUD, Philippe. Pedagogia Diferenciada: Das intenções à Ação. 2000. Disponível em: $<$ https://www.docsity.com/pt/2-05-pedagogia-diferenciada-philippe-perrenoud-1/4906535/>. Acesso em: 07 out. 2019.

Teoria das Competências. 1999. Disponível em: <http://www2.videolivraria.com.br/pdfs/14867.pdf>. Acesso em: 08 out. 2019.

SENAI. Departamento Nacional. Metodologia SENAI de educação profissional. Disponível em: http://senaiweb.fieb.org.br/areadocente/assets/Midia/2019/Livro_Msep_2019.pdf. Acesso em 12 out. 2019.

VYGOTSKY, Lev Semenovich; LEONTIEV, Alexis N.; LURIA, Alexander Romanovich. Linguagem, desenvolvimento e aprendizagem. 2010. ícone Editora Ltda. Disponível em: <https://www.unifalmg.edu.br/humanizacao/wp-content/uploads/sites/14/2017/04/VIGOTSKI-Lev-Semenovitch-LinguagemDesenvolvimento-e-Aprendizagem.pdf>. Acesso em: 08 out. 2019.

Informações sobre os autores: ROCD: Licenciado em Pedagogia (2019) pelo Centro Universitário de Mineiros (UNIFIMES), Mineiros - GO, Brasil.

Contribuição dos autores: ROCD: conceitualização, captação de recursos, supervisão, redação. 